\title{
離散渦法を用いた水中トンネルの動的安定性に関する検討
}

Study on the Stability of the Submerged Floating Tunnels by Discrete Vortex Method

神部 俊一* 野田 稔* 巽 茂樹** 戸田 茂之***

Shunichi Kanbe, Minoru Noda, Shigeki Tatsumi, Shigeyuki Toda

Anstract

In this paper, the fluid dynamic stability of the submerged floating tunnel with eliptical crosssection was investigated. It was found from fluid dynamic analysis using the discrete vortex method that the Strouhal number of this model under the post-supercritical region of Reynolds number is 0.24 approximately, and the lift and moment coefficient have a positive gradient. We found from the free vibration analysis that the minimum natural frequency of the structural models is about 7 times as high as the vortex shedding frequency. The numerical analysis indicated that the structural models are stable for the fluid dynamic vibration.

Keywords : submerged floating tunnel, discrete vortex method, vortex-induced vibration

1.はじめに

現在、海峡や離島などに対する長距離の渡海手段として、長大橋梁・海底トンネルが主に用いられている。し かし、長大橋梁は、自重の増大から構造的な限界スパンにほぼ達しており、海底トンネルも地質や耐震性などの 条件によって距離に比例して建設するのが困難になる。このため、より長距離の渡海手段として既存の構造形式 を採用することは難しく、水中トンネルのような新しい構造形式の渡海手段が必要になると予想される。水中下 ンネルは完全に没水した状態で設置されるので、その排水量に起因する浮力が構造本体の支持力として機能し、 長大橋梁のような自重による構造的限界はない。また、海底地盤の地質や地形にも左右されにくいため、今後の 渡海手段として大いに期待できる構造形式である。

しかし、上記のように長距離の渡海手段として水中トンネルを考える場合、波浪による流体力に加えて、潮流 による流体力を考慮することが不可欠である。特に、水中トンネル構造本体の形状は、内部に交通路を収容する 空間を確保する必要から鈍頭物体となるため、後流に Karman 渦状の周期渦が発生する可能性が高くなり、渦励 振と呼ばれる流体力学的な不安定現象が発生する恐れがある。この問題を検討するためには、水中トンネルに作 用する非定常流体力の特性と、水中トンネルの自由振動特性とを比較すればよい。しかし、対象となる流体現象 が $10^{7}$ といら極めて高いレイノルズ数領域となるため、風洞実験などを通じて実験的に検討することは困難であ る。そこで、本研究では、高レイノルズ数領域の流体解析に適している離散渦法 1)を用いて非定常流体力を求め、 想定する水中トンネルの動的安定性について検討した。

\section{2. 想定モデル}

図 1 に本研究で想定した水中トンネルの断面図を示す。水中トンネル本体(以後、構造本体と呼ぶ)は、長径 $20 \mathrm{~m}$ 、 短径 $10 \mathrm{~m}$ の楕円形断面を有する鉄筋コンクリート製の函体である。また、内部には交通路用として $5.5 \mathrm{~m} \times 4.5 \mathrm{~m}$ の空間を 2 つ確保している。表 1 に示す 4 種類の断面モデルは、浮力と自重がほぼ釣り合うように外壁および内 壁の厚さが定められている。

一方、構造本体は図 2 に示寸ように、水梁 $70 \mathrm{~m}$ の海域で水面下 $35 \mathrm{~m}$ に設置され、平面トラス状の係留系によっ て支持されている。係留系を構成する各部材は、直径 $1,016 \mathrm{~mm}$ ，肉厚 $16 \mathrm{~mm}$ の鋼管である。各部材はユニバーサ ルジョイントによって結合されているため、結合部では任意の回転軸まわりに自由に回転できるようになってい る。ここでは、図 3 に示すような 1 径間 $120 \mathrm{~m}$ 、連続 5 径間の全体系モデルを設定して自由振動解析を行った。

\section{3. 自由振動特性}

自由振動解析では、図 4 に示寸ように、係留系を $x$ 軸まわりの回転ばねおよび $y, z$ 方向の変位ばねから成る複 合ばね系としてモデル化した。ここで、係留系が左右対称であることを考慮すると、構造本体の重心の変位（ $v_{G}$,

\begin{tabular}{rllll}
\hline$*$ & 正会員 & 鳥取大学工学部土木工学科 & $(680$ & 鳥取市湖山町南 4-101) \\
$* *$ & 非会員 & 駒井鉄工 (株) & & \\
$* * *$ & 学生会員 & 鳥取大学大学院 & &
\end{tabular}




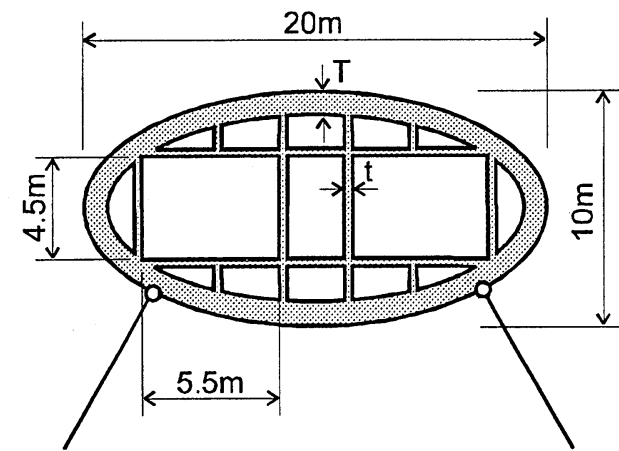

表 1 想定した水中トンネルの諸元

図 1 水中トンネル断面図

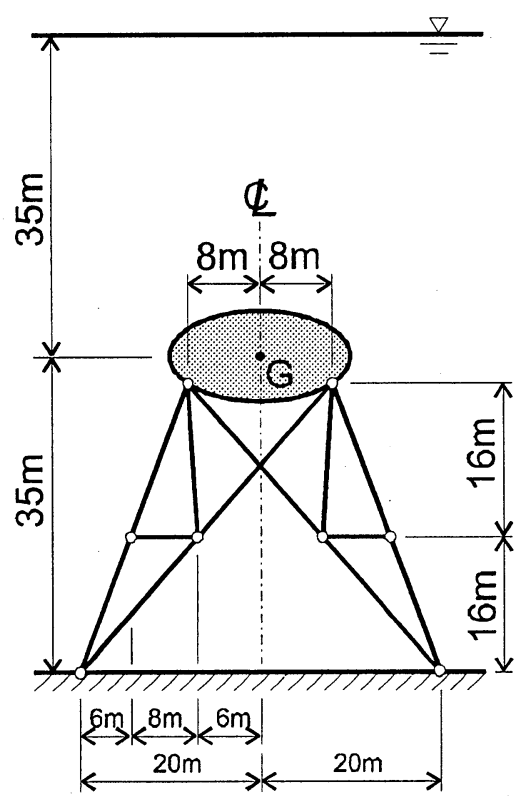

図 2 係留系概略図

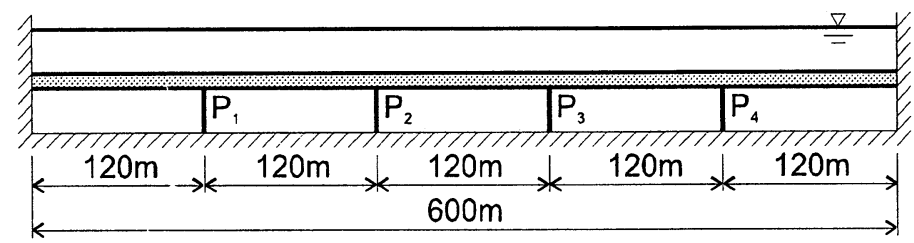

図 3 全体系モデル

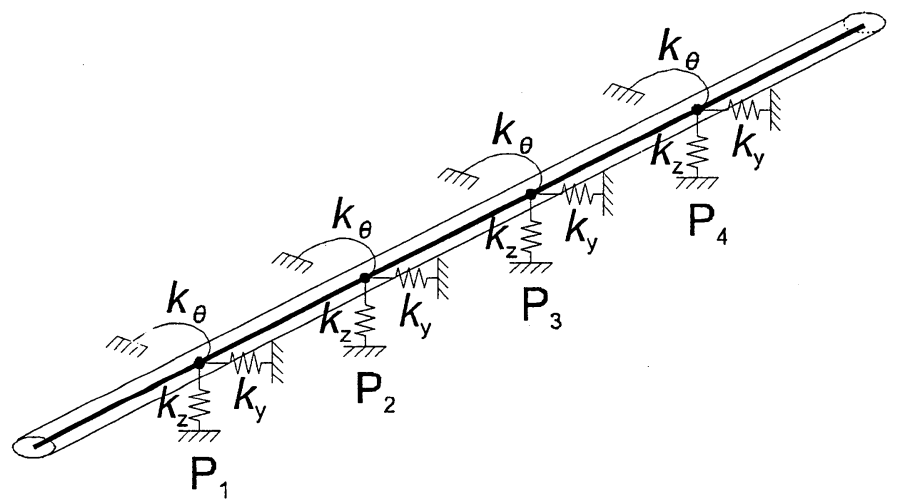

図 4 自由振動解析モデル

$\left.w_{G}, \theta_{x G}\right)$ と係留系が本体に及ぼす係留力を重心に変換した力 $\left(F_{y G}, F_{z G}, T_{x G}\right)$ との間には次式が成立する。

$$
\left\{\begin{array}{l}
F_{y G} \\
F_{z G} \\
T_{x G}
\end{array}\right\}=\left[\begin{array}{ccc}
k_{y y} & 0 & k_{y \theta} \\
0 & k_{z z} & 0 \\
k_{\theta y} & 0 & k_{\theta \theta}
\end{array}\right]\left\{\begin{array}{c}
v_{G} \\
w_{G} \\
\theta_{x G}
\end{array}\right\}
$$

このことから、構造本体の水平並進振動とねじれ振動は連成振動となり、鉛直振動は独立していることがわかる。 また、構造本体の付加質量としては、長径 $a$, 短径 $b$ の楕円柱体に対してポテンシャル理論により求められる次 式 ${ }^{2)}$ 用いた。

$$
\left.\begin{array}{l}
m_{y}=\pi \rho_{w} b^{2} \\
m_{z}=\pi \rho_{w} a^{2} \\
m_{\theta}=\frac{1}{8} \rho_{w}\left(a^{2}-b^{2}\right)^{2}
\end{array}\right\}
$$

また、構造本体の両端が固定支持されているものとして境界条件を与えた。

以上の条件で、構造本体を部分構造に分割してその両端に互いに向き合う座標系を設定し、部分構造の両端か

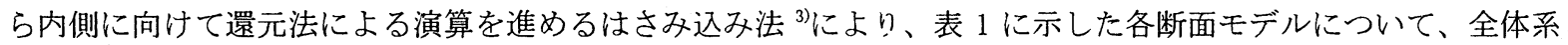
の鉛直曲げ振動および水平曲げ・ねじれ連成振動の固有振動数を求めた。

ここで、解析結果の一例として、モデル A の振動モード形を図 5 に示す。また、表 2,3 に全ての断面モデルに ついて得られた鉛直曲げ振動および水平曲げ・ねじれ連成振動の 1 ～次の対称・逆対称モードの固有振動数を示 す。これらの結果から、構造本体の外壁、内壁の厚みによる固有振動数の変化は小さく、最も低い振動数で $0.17 \mathrm{~Hz}$ 程度となる結果が得られた。 


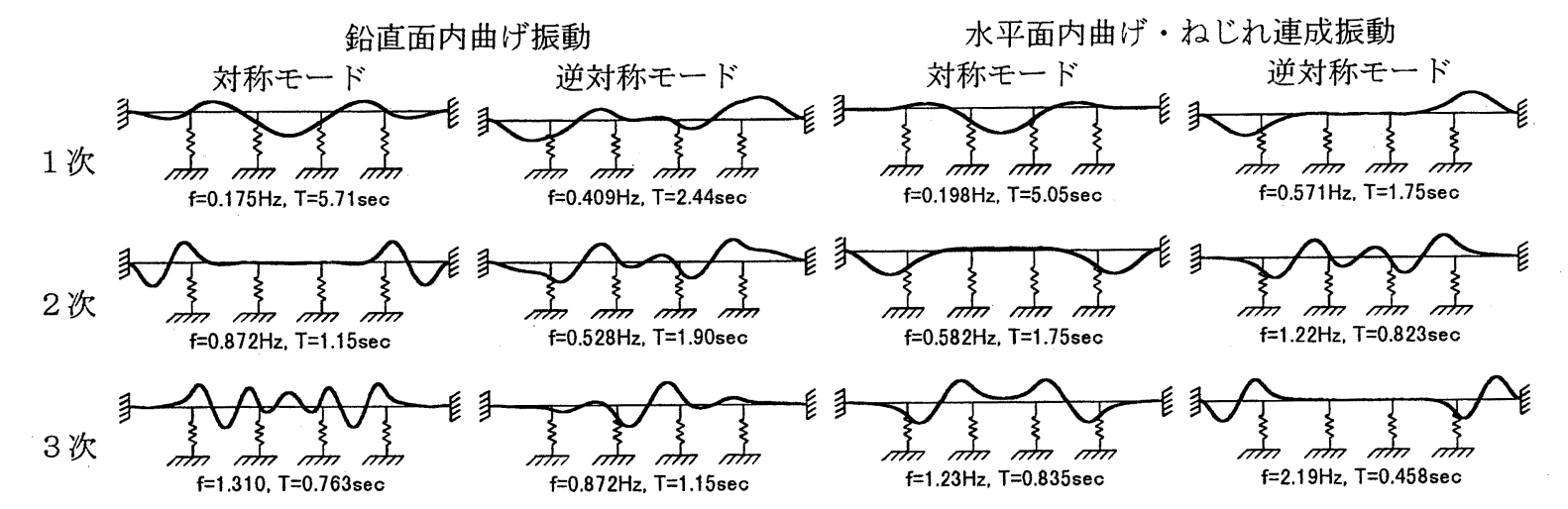

図5 水中トンネル全体系の鉛直面内曲げ振動および水平面内曲げ・ねじれ連成振動のモ一ド形（Model A)

表2 各断面モデルにおける鉛直面内曲げ振動の固有振動数 $(\mathrm{Hz})$

\begin{tabular}{|c|c|c|c|c|c|c|c|c|}
\hline \multirow{2}{*}{} & \multicolumn{2}{|c|}{ Model A } & \multicolumn{2}{c|}{ Model B } & \multicolumn{2}{c|}{ Model C } & \multicolumn{2}{c|}{ Model D } \\
\cline { 2 - 9 } & 対称 & 逆対称 & 対称 & 逆対称 & 対称 & 逆対称 & 対称 & 逆対称 \\
\hline 1 次 & 0.175 & 0.409 & 0.174 & 0.415 & 0.174 & 0.435 & 0.172 & 0.442 \\
\hline 2 次 & 0.872 & 0.528 & 0.878 & 0.530 & 0.902 & 0.543 & 0.909 & 0.546 \\
\hline 3 次 & 1.31 & 0.872 & 1.32 & 0.878 & 1.36 & 0.902 & 1.41 & 0.909 \\
\hline
\end{tabular}

表3 各断面モデルにおける水平面内曲げ·ねじれ連成振動の固有振動数 $(\mathrm{Hz})$

\begin{tabular}{|c|c|c|c|c|c|c|c|c|}
\hline \multirow{2}{*}{} & \multicolumn{2}{|c|}{ Model A } & \multicolumn{2}{c|}{ Model B } & \multicolumn{2}{c|}{ Model C } & \multicolumn{2}{c|}{ Model D } \\
\cline { 2 - 9 } & 対称 & 逆対称 & 対称 & 逆対称 & 対称 & 逆対称 & 対称 & 逆対称 \\
\hline 1 次 & 0.198 & 0.571 & 0.197 & 0.575 & 0.197 & 0.582 & 0.195 & 0.580 \\
\hline 2 次 & 0.571 & 1.22 & 0.575 & 1.23 & 0.582 & 1.25 & 0.580 & 1.25 \\
\hline 3 次 & 1.20 & 2.19 & 1.21 & 2.21 & 1.23 & 2.24 & 1.23 & 2.24 \\
\hline
\end{tabular}

\section{4. 流体解析}

\section{1 解析手法}

本研究で想定している水中トンネルの場合、レイノルズ数は $10^{7}$ 程度となり、円断面であれば極超臨界レイノ ルズ数の範囲である。しかし、このレイノルズ数領域における楕円断面の流体力特性についての実験データはほ とんどなく、また実験的に求めることは困難を極める。そこで、本研究では想定している楕円断面の非定常流体 力特性を数值解析によって推定することにした。ここでは、高レイノルズ数領域の流体解析に適しているとされ ている離散渦法を用いて数值解析を行った。本研究の流体解析で用いた離散渦法は、一様流のポテンシャル場お よび物体表面の境界層、剥離剪断層を近似する渦点のポテンシャル場を重ね合わせることによって、剥離の伴う 流れ場を表現する特異点分布法である。

ここで図 6 に離散渦法の概略図を示す。図のように一様流と物体表面上に配置した $M$ 個の渦点、および剥離剪 断層を近似する $N$ 個の渦点による流れ場の座標 $z$ における複素速度ポテンシャルは次式で示される。

$$
f(z)=U e^{-i \alpha} \cdot z+\frac{1}{2 \pi i} \sum_{j=1}^{M} \Gamma_{B j} \log \left(z-z_{B j}\right)+\frac{1}{2 \pi i} \sum_{j=1}^{N} \Gamma_{S j} \log \left(z-z_{S j}\right)
$$

ここに、Uは一様流速、 $\alpha$ は解析座標系に対する一様流の迎え角、 $\Gamma_{j}, z_{j}$ はそれぞれ渦点のもつ循環の強さおよ び座標を表す。なお、式中の添え字 Bおよび S は、それどれ物体表面上に配置された渦点、剥離剪断層を近似す る渦点の物理量であることを表している。このうち、未知量は物体表面上に配置された渦点の循環であり、物体 表面における不透過条件と Kelvin の循環保存則を満たすように決定される。

次に、剥離剪断層を近似する渦点は物体表面の剥離点に設けた渦放出点から計算時間間隔 $\Delta t$ 毎に放出される。 ここで放出された渦点は、時刻 $t$ における渦点の位置の誘起速度 $\left(u_{s}, v_{s}\right)$ を用いた次式によって $\Delta t$ 時間後におけ る位置を決定し、逐次移動させた。

$$
\left.\begin{array}{l}
x_{S}(t+\Delta t)=x_{S}(t)+u_{S}(t) \cdot \Delta t \\
y_{S}(t+\Delta t)=y_{S}(t)+v_{s}(t) \cdot \Delta t
\end{array}\right\}
$$



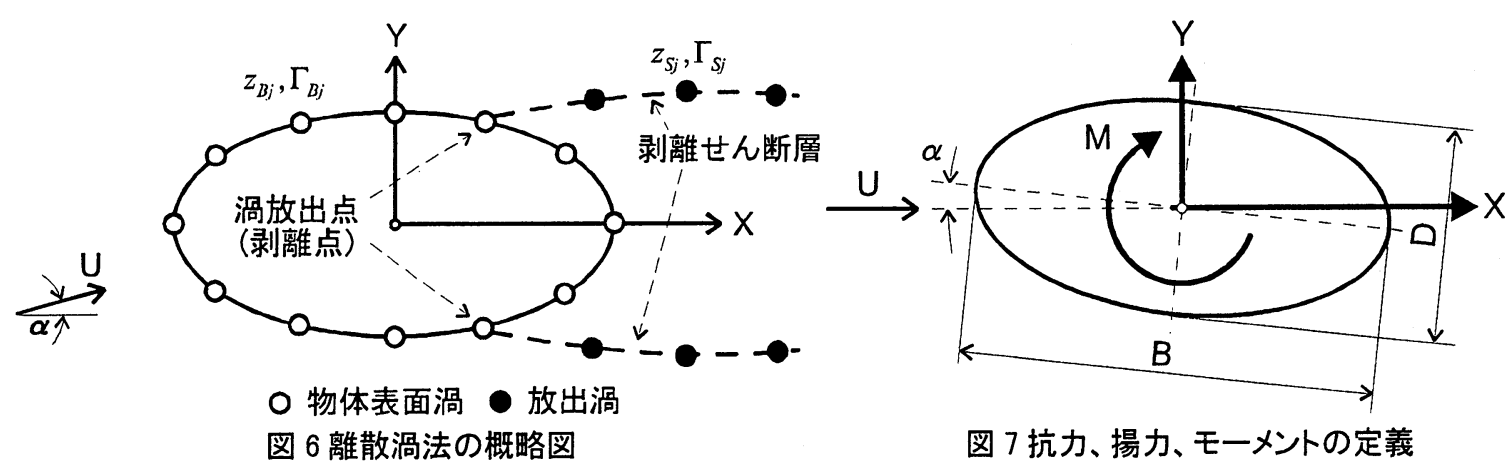

図 7 抗力、揚力、モーメントの定義

放出渦の循環の強さは、渦放出点における物体表面渦の循環 $\Gamma_{B}$ 元に、剥離剪断層の循環密度を考慮した次式 ${ }^{4)}$ によって決定した。

$$
\Gamma_{S}=\frac{\Gamma_{B}}{\Delta s} \cdot U_{s} \Delta t
$$

ここで、 $\Delta s$ は渦放出点における渦点が代表する物体表面要素の長さ、 $U_{s}$ は渦放出点における誘起速度である。

本研究では上記の方法によって流れ場を解析し、その結果に基づいて図 7 に示寸非定常流体力を求めた。非定 常流体力の算出については、抗力 $X$ 、揚力 $Y$ は稲室氏による提案式 ${ }^{5)}($ 式 6)、モーメント $M$ については宇都宫ら の提案式 ${ }^{6)}$ (式 7)去用いた。

$$
\begin{aligned}
& X-i Y=i \rho\left[U e^{-i \alpha}\left(\sum_{j=1}^{M} \Gamma_{B j}+\sum_{j=1}^{N} \Gamma_{S j}\right)-\frac{d}{d t}\left(\sum_{j=1}^{M} \Gamma_{B j} \bar{z}_{B j}+\sum_{j=1}^{N} \Gamma_{S j} \bar{z}_{S j}\right)\right] \\
& M=\rho \operatorname{Re}\left[\sum_{j=1}^{M} \Gamma_{B j} z_{B j} \frac{d \bar{z}_{S j}}{d t}+\sum_{j=1}^{N} \Gamma_{S j} z_{S j} \frac{d \bar{z}_{S j}}{d t}-U e^{-i \alpha}\left(\sum_{j=1}^{M} \Gamma_{B j} z_{B j}+\sum_{j=1}^{N} \Gamma_{S j} z_{S j}\right)\right]
\end{aligned}
$$

また、求められた流体力を、最終的に次式で定義される流体力係数として評価した。

$$
\left.\begin{array}{rl}
C_{D} & =X /\left(\frac{1}{2} \rho U^{2} D\right) \\
C_{L} & =Y /\left(\frac{1}{2} \rho U^{2} D\right) \\
C_{M} & =M /\left(\frac{1}{2} \rho U^{2} B^{2}\right)
\end{array}\right\}
$$

ここで、 $D, B$ はそれぞれ楕円の短径，長径である。

\section{2 解析条件}

本研究で対象としているような表面が滑らかな曲面を有する断面形状の場合、高レイノルズ数領域における剥 離点は流れの状態に応じて移動することが知られており、矩形柱のように明確な剥離点は存在しない。円断面を 対象とした実験結果および解析結果 》によれば、極超臨界領域における剥離点は、上流側よどみ点から $115^{\circ}$ 付近 となることが明らかにされているが、想定している棈円断面については剥離点に関する検討例がない。そこで、 本研究では円断面における上述の剥離点位置を Joukowski 変換によって楕円座標系に等角写像し、剥離点を決定 した ${ }^{8)}$ 。また、離散渦法では計算時間間隔の設定によ二て解析結果が左右されるため、その影響も考慮する必要 がある。そこで、本研究では計算時間間隔 $\Delta t を 0.05,0.10,0.15$ に設定し、それぞれについて解析することにした。 さらに、迎え角がつくことによって非定常流体力特性に変化が起こるかどうかを確認するために、迎え角を 0〜 $5^{\circ}$ の範囲で変化させた。

\section{$4: 3$ 解析結果}

解析結果の一例として、 $\Delta t=0.10, \alpha=0^{\circ}$ における放出渦の流下状況および流線を図 8 に示す。基本的なフロー パターンについては、剥離した流れが構造本体直後ですぐに巻き込まず、ある程度流下してから Karman 渦状の 流れに移行する傾向があることが、今回行った解析のすべての計算条件において確認された。また、Karman 渦状 の流れ、移行する場所は計算時間間隔が大きくなるにつれて下流、移動し、同時に流線の蛇行する幅が小さくな る傾向が認められた。これは式 (4)で示したように放出渦の移動が一次精度となっているため、計算時間間隔を 大きくすることで渦の運動に対する誤差が大きくなるためと考えられる。

次に、各計算時間間隔において得られた三分力特性を図 9 に、た各流体力係数の波形の一例として、 $\Delta t=0.10$, 


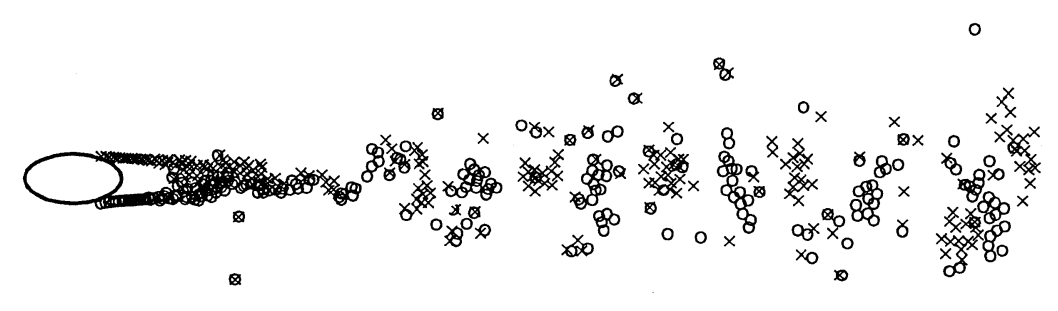

（a）放出渦の流下状況

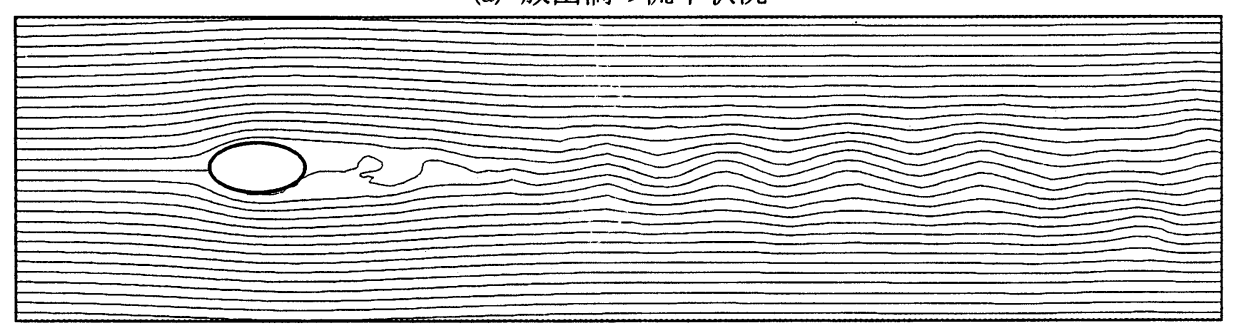

(b) 流線

図8 放出渦の流下状況および流線 $\left(d t=0.10, \alpha=0^{\circ}, t U / D=80\right)$
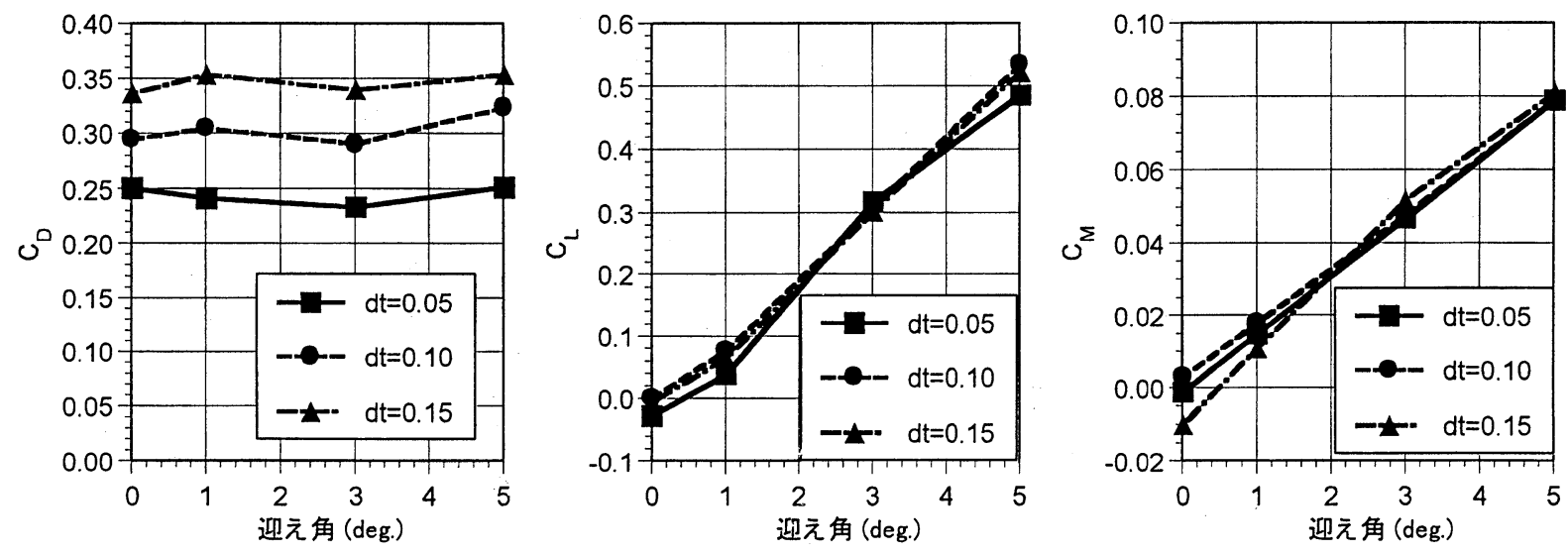

図9 各計算時間間隔における三分力特性の変化

$\alpha=0^{\circ}$ における解析結果を図 10 に示す。図 9 の結果によると抗力係数 $C_{D}$ が計算時間間隔によって変化している が、揚力係数 $C_{L}$ およびモーメント係数 $C_{M}$ については計算時間間隔による差はほとんじ認められない。迎え角の 变化に対する各流体力係数の挙動は、抗力係数はほぼ一定、揚力係数およびモーメント係数については正勾配で 迎え角の増加に対してほほ直線的となる結果が得られ志。各流体力係数ひ时間的な変化についいては、図 10 ふらも わかるように平均值的には時間の経過に対してきわめて安定しており、揚力係数およびモーメント係数が周期的 な変動をしている結果が得られた。この性状は、すべての計算条件で認められたが、計算時間間隔の増加に従っ てその振幅は小さくなる傾向となった。なお、波形にスパイク状の変動が認められるが、これは物体境界内に飛 び込んだ渦の消去や、渦の異常接近による誘起速度の増大が原因であるため、現実に起こる変動ではないと考え られる。

ここで、非定常流体力の周波数特性の一例として、図 10 に示した揚力係数の波形より求めたパワースペクトル を示す。この図からもわかるように、パワースペクトルには明確なピークが現れており、その無次元化周波数 $f D / U$ は 0.23 0.25 の值が得られた。このことから本研究で対象としている水中トンネルの断面形状ではストロ 一ハル数 $S t=f D / U$ も 0.24 前後の值になることが推測できる。

\section{5. 水中トンネルの流体力学的な動的安定性}

一般に、流れの中で発生すると考えられる流体力学的な振動は、Karman 渦のような周期的な渦の発生により生 じる渦励振と、断面形状によって決定される流体力特性によって発生するフラッター振動が存在する。前者につ いては、ストローハル数より導かれる渦の発生周波数と構造物の固有振動数を比較することによって、振動発生 の可能性を照査することができ、後者の現象については、準定常理論を適用できる範囲であれば三分力特性から 

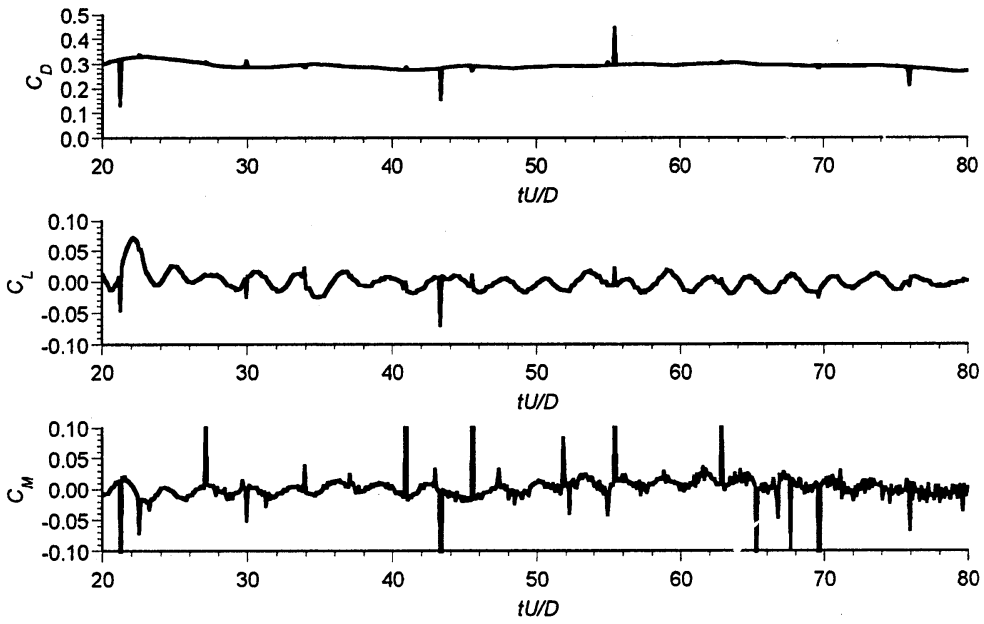

図 10 構造本体に作用する非定常流体力 $\left(d t=0.10, \alpha=0^{\circ}\right)$

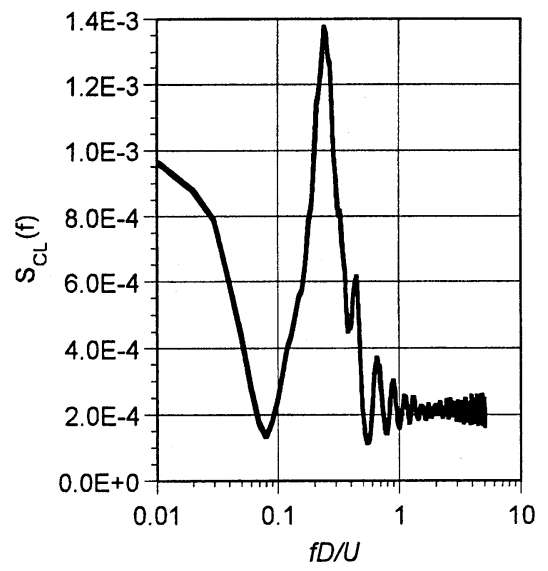

図 11 揚力係数の周波数特性 $\left(d t=0.10, \alpha=0^{\circ}\right)$

現象の発生の有無を照査寸ることができる。ここで、それぞれの振動現象の発生の可能性について検討する。

先の流体解析の結果より、本研究で想定している水中トンネルのストローハル数は 0.24 程度となることから、 代表寸法である $D=10(\mathrm{~m})$ をストローハル数の定義 $S t=f D / U$ に代入し、渦の発生周波数と流速の関係を求めると、 $f=0.024 U$ となる。自由振動解析の結果によると、本研究で想定した水中トンネルの全体系の固有振動数は最も 低いもので $0.17 \mathrm{~Hz}$ であり、渦の発生周波数が構造系の固有振動数となる流速は $7.1 \mathrm{~m} / \mathrm{s}$ となる。想定した水樑に おける潮流の流速が $1.0 \mathrm{~m} / \mathrm{s}$ 程度であることを考えると、構造系の固有振動数は渦の発生周波数に比へてききわ的 高いものであることから、渦励振が発生する可能性は低いと判断できる。

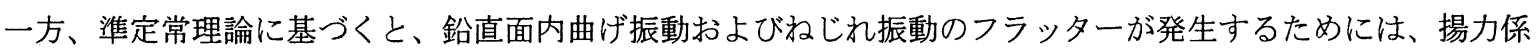
数またはモーメント係数が迎え角の増加に対して負の勾配を持つ必要がある。今回行った流体解析の結果による と、両者とも正の勾配を有していることから、本研究で想定した楕円断面がフラッター現象に対してもきわめて 安定した形状であることがわかる。

\section{6. まとめ}

本研究では、自由振動解析と流体解析を通じて棈円断面を有する水中トンネルの流体力学的な動的安定性につ いて検討した。その結果、想定した水中トンネルは、流体力学的な振動である渦励振やフラッター現象に対して、 きわわて安定した構造的・流体力学的特性を有しており、海狭部のような流速の高い地点に設置しても、振動が 発生する可能性は低いことが明らかになった。

\section{謝辞}

本研究の遂行に当たって有益なご意見をいただいた、鳥取大学久保昇三教授に感謝の意を表します。

\section{参考文献}

1) 坂田, 足立, 稲室 : “渦放出モデルを用いたはく離をともなう非定常流れの一解法（第一報, 単独正方形柱周り の流れ)”, 日本機械学会論文集 (B 集), 49 巻, 440 号, 1983.

2) 東 昭 : ”機械工学選書 航空工学 I-航空流体力学-“, 裳華堂.

3) 神部，田中，甲斐：“はさみ込み法による多室断面鋼製箱桁の断面変形挙動解析”，構造工学論文集，Vol.34A, 1989.

4) 野田, 神部 : “㣶環密度の概念を導入した渦点法に関する考察”, 第 52 回土木学会年次学術講演会概要集, 1997.

5) 稲室 : “渦点法における物体表面に作用する流体力の一定式化”, 日本航空宇宙学会誌, 33, 1985.

6) 宇都宫, 長尾, 村田 : “渦点法による振動物体に作用する空気力の推定”, 第 14 回風工学シンポジウム論文集, 1996.

7)稲室, 足立 : “うず放出モデルを用いたはく離を伴う非定常流れの一解法 (第 2 報), 単独円柱周りの流れ)”, 日 本機械学会論文集 (B 編), 52 巻, 476 号, 1986.

8) 神部, 加藤 : “潮流力作用下の水中橋梁に関寸る考察”, 第 49 回土木学会年次学術講演会概要集, 1994. 